\title{
Resolution of Pregabalin and Mirtazapine Associated Restless Legs Syndrome by Bupropion in a Patient with Major Depressive Disorder
}

\section{Young-Min Park ${ }^{1}$ \\ Heon-Jeong Lee L,3 $^{2,3}$ \\ Seung-Gul Kang ${ }^{2}$ \\ Jae-Hyuck Cho ${ }^{1}$ \\ Leen $\mathrm{Kim}^{2}$}

${ }^{1}$ Department of Neuropsychiatry, Inje University College of Medicine, Ilsan Paik Hospital, Goyang, 2Department of Psychiatry, Anam Hosipital

3Division of Brain Korea 21 Biomedical Science, Korea University College of Medicine, Seoul, Korea

\section{Correspondence}

Young-Min Park, MD, PhD

Department of Neuropsychiatry,

Inje University College of Medicine,

Ilsan Paik Hospital, 2240 Daehwa-dong,

Ilsanseo-gu, Goyang 411-706, Korea

Tel $+82-31-910-7260$

Fax +82-31-910-7268

E-mail medipark@hanmail.net

(c) This is an Open Access article distributed under the terms of the Creative Commons Attribution Non-Commercial License (http://creativecommons.org/licenses/by-nc/3.0) which permits unrestricted non-commercial use, distribution, and reproduction in any medium, provided the original work is properly cited.

\begin{abstract}
Bupropion is a selective norepinephrine and dopamine reuptake inhibitor with no serotonergic activity, and is therefore an antidepressant with unique pharmacological properties. There are some reports that selective serotonin reuptake inhibitors (SSRIs) or mirtazapine can induce adverse effects including restless legs syndrome (RLS) and that bupropion can reverse these adverse effects. Here, we report about a patient with a major depressive disorder who exhibited RLS after being treated with pregabalin and mirtazapine. This adverse effect disappeared after having switched from mirtazapine to bupropion. Bupropion inhibits the reuptake of dopamine and increases dopamine neurotransmission in both the nucleus accumbens and the prefrontal cortex. This pharmacological profile can be effective in patients with RLS related to dopamine hypoactivity. However, the limitations of this single case report mean that further investigations with larger samples are needed.
\end{abstract}

Psychiatry Invest 2009;6:313-315

Key Words Restless legs syndrome, Bupropion, Pregabalin, Mirtazapine.

Received: July 26, 2009 Revised: August 19, 2009 Accepted: September 11, 2009

Available online: November 19, 2009

\section{Introduction}

Restless legs syndrome (RLS), which is characterized by an unpleasant sensation in the legs that results in an urge to move them, is often either undiagnosed or misdiagnosed as a psychiatric, other neurological, muscular, or orthopedic condition. RLS is also characterized by worsening of symptoms at rest and in the evening or night. Many patients with RLS also exhibit periodic limb movement during sleep and relaxed wakefulness. ${ }^{1}$ This disorder can cause severe insomnia and mood disturbances, and has an adverse impact on the patient's quality of life. ${ }^{2}$ The cause of RLS is not yet clear, but one of the more promising theories involves the body's dopamine system.

Most RLS cases are idiopathic. Secondary RLS is observed in the patients with diabetes mellitus, renal failure, iron-deficiency anemia, polyneuropathy, and rheumatoid arthritis. ${ }^{3}$ Medication-induced RLS remains an underdiagnosed etiology of secondary RLS. However, antidepressants have long been known to exacerbate RLS. ${ }^{4}$

The prescription of the new antidepressants such as, selective serotonin reuptake inhibitors (SSRIs), serotonin-norepinephrine reuptake inhibitors (SNRIs), and noradrenergic and specific serotonergic antidepressants (NaSSAs), is increasing compared to that of tricyclic antidepressants. These antidepressants have become a firstline treatment option for millions of patients due to their good balance between efficacy and tolerability. However, some adverse effects associated with their use such as, weight gain, sexual dysfunction, RLS, and emotional detachment, can impair the quality of life and compliance with treatment. ${ }^{5,6}$ Because it appears that these adverse 
effects are mainly associated with serotonin, many clinicians have moved toward the use of bupropion. Bupropion does not affect serotonin or postsynaptic receptors, and it is therefore an antidepressant with unique pharmacological properties. ${ }^{7}$ There are some reports that SSRIs or mirtazapine can induce RLS and that bupropion can reverse this adverse effect. ${ }^{8}$ Here, we report about a patient with a major depressive disorder who exhibited RLS after being treated with pregabalin and mirtazapine. This adverse effect disappeared after having switched from mirtazapine to bupropion.

\section{Case}

A 64-year-old Korean female was admitted to our hospital in 2003 due to the onset of a depressive episode. She had been treated by a local psychiatric practitioner with sertraline for 15 years. The presenting symptoms were suicidal ideation, avolition, insomnia, depressed mood, and fatigue. During her admission, we replaced sertraline with mirtazapine. Her acute symptomatology had largely remitted after 1 month of hospital treatment, and hence she was discharged to day-clinic treatment. We maintained her on 15-45 mg of mirtazapine daily for 5 years, with the daily dose being reduced to $15 \mathrm{mg}$ because of her stability.

Her general practitioner prescribed pregabalin at 300 $\mathrm{mg}$ /day due to shoulder and back pain in April 2008, and this induced an uncomfortable sensation in both legs at rest 1 week later. The unpleasant sensation worsened at night and could be relieved by moving the legs. The patient met the diagnostic criteria for RLS published by the International RLS Study Group (IRLSSG). ${ }^{9}$ The severity of her RLS symptoms was scored as 26 points on RLS rating scale, ${ }^{10}$ which comprises 10 items scored from 0 to 4 points with highest possible score of 40 points. She did not have any other disease related to secondary RLS. She also had no organic brain disease and was taking no medication except mirtazapine and pregabalin. All of her routine laboratory parameters including iron (125 $\mu \mathrm{g} / \mathrm{dL})$, ferritin $(81 \mathrm{ng} / \mathrm{mL})$, and TIBC $(234 \mu \mathrm{g} / \mathrm{dL})$ were within normal limits. We recommended her to stop taking pregabalin, but she refused because it was effective against her shoulder and back pain.

To treat her RLS, in May 2008 we replaced mirtazapine with bupropion SR at $150 \mathrm{mg}$ daily, but we could not discontinue pregabalin because she wanted to continue it. The patient's RLS symptoms improved substantially such that by day 28 following commencement of bupropion SR therapy, her RLS symptom score was 14 points. Her RLS symptoms totally disappeared in August 2008 when we increased bupropion to $300 \mathrm{mg}$ (Wellbutrin XL) daily.
Her score had decreased to zero. She did not report any other RLS symptoms. The follow-up visit 1 month revealed no further symptoms of RLS.

\section{Discussion}

Bupropion is the only antidepressant that exerts effects on both norepinephrine and dopamine neurotransmitters with no known serotonergic activity. ${ }^{11}$ Thus, unlike SSRIs and mirtazapine, it is not associated with adverse effects such as RLS and sexual dysfunction. Indeed, bupropion can reverse these conditions by altering dopaminergic activity. 5,6

It was reported that RLS was a common side effect (28\%) during application of mirtazapine. ${ }^{4}$ After the administration of mirtzapine and pregabalin, her RLS symptoms had appeared. Thus, this might be the first case supporting the hypothesis that the combined administration of mirtazapine and pregabalin is related to the onset of RLS. However, it is also possible that pregabalin alone is responsible for the onset of RLS because mirtazapine alone, when administered from 2003 to 2008, did not cause any RLS symptoms. She did not experience RLS symptoms during mirtazapine treatment, but these presented immediately after she was treated with pregabalin in April 2008. Therefore, it is possible that pregabalin can induce RLS. However, it remains open as to whether the combination or even pregabalin alone is responsible for RLS.

There has been a single case report of pregabalin inducing myoclonus, ${ }^{12}$ but there has been no previous report of pregabalin inducing RLS. However, pregabalin could theoretically induce RLS because it binds potently to the $\alpha_{2}-\delta$ subunit and modulates calcium influx at nerve terminals, and thereby reduces the release of several neurotransmitters including glutamate, norepinephrine, serotonin, dopamine, and substance P. ${ }^{13-17}$ Furthermore, there has been a case report of RLS being induced by zonisamide, which is a type of anticonvulsant like pregabalin. ${ }^{18}$ However, it was reported that pregabalin was effective in the treatment of secondary RLS for patients with neuropathic pain in a recent open trial. ${ }^{19}$ Therefore, whether pregabalin can induce RLS or not remains controversial.

Bupropion inhibits the reuptake of dopamine and increases dopamine neurotransmission in both the nucleus accumbens and the prefrontal cortex. ${ }^{11}$ This pharmacological profile can be effective in patients with RLS related to dopamine hypoactivity. ${ }^{8,20}$ However, it remains open as to whether the discontinuation of mirtazapine or the addition of bupropion is responsible for the improvement of RLS symptoms. The limitations of this single case report mean that further investigations with larger 
samples are needed.

\section{REFERENCES}

1. Montplaisir J, Boucher S, Poirier G, Lavigne G, Lapierre O, Lespérance P. Clinical, polysomnographic, and genetic characteristics of restless legs syndrome: a study of 133 patients diagnosed with new standard criteria. Mov Disord 1997;12:61-65.

2. Allen RP, Walters AS, Montplaisir J, Hening W, Myers A, Bell TJ, et al. Restless legs syndrome prevalence and impact: REST general population study. Arch Intern Med 2005;165:1286-1292.

3. Glasauer FE. Restless Legs Syndrome. Spinal Cord 2001;39:125-133.

4. Rottach KG, Schaner BM, Kirch MH, Zivotofsky AZ, Teufel LM, Gallwitz T, et al. Restless legs syndrome as side effect of second generation antidepressants. J Psychiatr Res 2008;43:70-75.

5. Demyttenaere K, Jaspers L. Review: bupropion and SSRI-induced side effects. J Psychopharmacol 2008;22:792-804.

6. Rottach KG, Schaner BM, Kirch MH, Zivotofsky AZ, Teufel LM, Gallwitz T, et al. Restless legs syndrome as side effect of second generation antidepressants. J Psychiatr Res 2008;43:70-75.

7. Ferris RM, Cooper BR. Mechanism of antidepressant activity of bupropion. J Clin psychiatry Monograph 1993;11:2-14.

8. Kim SW, Shin IS, Kim JM, Yang SJ, Shin HY, Yoon JS. Bupropion may improve restless legs syndrome: a report of three cases. Clin Neuropharmacol 2005;28:298-301.

9. Allen RP, Picchietti D, Hening WA, Trenkwalder C, Walters AS, Montplaisi J, et al. Restless legs syndrome: diagnostic criteria, special considerations, and epidemiology. A report from the restless legs syndrome diagnosis and epidemiology workshop at the National Institutes of Health. Sleep Med 2003;4:101-119.

10. Walters AS, LeBrocq C, Dhar A, Hening W, Rosen R, Allen RP, et al. Validation of the International Restless Legs Syndrome Study Group rating scale for restless legs syndrome. Sleep Med 2003;4:121-132.

11. Stahl SM, Pradko JF, Haight BR, Modell JG, Rockett CB, LearnedCoughlin S. A review of the neuropharmacology of bupropion, a dual norepinephrine and dopamine reuptake inhibitor. Prim Care Companion J Clin Psychiatry 2004;6:159-166.

12. Hellwig S, Amtage F. Pregabalin-induced cortical negative myoclonus in a patient with neuropathic pain. Epilepsy Behav 2008;13:418-420.

13. Cunningham MO, Woodhall GL, Thompson SE, Dooley DJ, Jones RS. Dual effects of gabapentin and pregabalin on glutamate release at rat entorhinal synapses in vitro. Eur J Neurosci 2004;20:1566-1576.

14. Errante LD, Petroff OA. Acute effects of gabapentin and pregabalin on rat forebrain cellular GABA, glutamate, and glutamine concentrations. Seizure 2003;12:300-306

15. Dooley DJ, Donovan CM, Pugsley TA. Stimulus-dependent modulation of $[(3) \mathrm{H}]$ norepinephrine release from rat neocortical slices by gabapentin and pregabalin. J Pharmacol Exp Ther 2000;295:1086-1093.

16. Dooley DJ, Mieske CA, Borosky SA. Inhibition of K(+)-evoked glutamate release from rat neocortical and hippocampal slices by gabapentin. Neurosci Lett 2008;280:107-110.

17. Fink K, Dooley DJ, Meder WP, Suman-Chauhan N, Duffy S, Clusmann $\mathrm{H}$, et al. Inhibition of neuronal $\mathrm{Ca}(2+)$ influx by gabapentin and pregabalin in the human neocortex. Neuropharmacology 2002;42: 229-236.

18. Velasco PE, Goiburu JA, Pinel RS. Restless legs syndrome induced by zonisamide. Mov Disord 2007;22:1517-1518.

19. Sommer M, Bachmann CG, Liebetanz KM, Schindehütte J, Tings T, Paulus W. Pregabalin in restless legs syndrome with and without neuropathic pain. Acta Neurol Scand 2007;115:347-350.

20. Lee JJ, Erdos J, Wilkosz MF, Laplante R, Wagoner B. Bupropion as a possible treatment option for restless legs syndrome. Ann Pharmacother 2009;43:370-374. 